\title{
Forensische diagnostiek in het civiele jeugdrecht; een zorg voor het Nederlands Instituut voor Forensische Psychiatrie en Psychologie (NIFP)
}

\author{
I.E. Troost*
}

\section{Het NIFP en het civiele jeugdrecht}

Door een aantal incidenten en de daaruit voortvloeiende aandacht voor kinderdoding staat kindermishandeling en kinderverwaarlozing volop in de belangstelling. Volgens de nationale prevalentiestudie naar kindermishandeling van de Universiteit Leiden uit 2007 is er sprake van 30 gevallen van kindermishandeling per 1000 kinderen. Deze $3 \%$ van de Nederlandse kinderen hebben vooral te maken met emotionele verwaarlozing. In Nederland overlijden waarschijnlijk jaarlijks 40 tot 50 kinderen door geweld van hun ouders. Daarvan komt minder dan de helft bij de strafrechter. Over deze ouders worden dan in een strafrechtelijk kader pro justitia-rapportages opgemaakt. In 2007 is de psycholoog Toon Verheugt gepromoveerd op dit onderwerp en hij gaf zijn proefschrift de titel 'Moordouders'. Het NIFP hoopt, door al eerder bij kindermishandeling te rapporteren, deze ernstige delicten te voorkomen. Het NIFP wil dat doen binnen de kaders van het civiele jeugdrecht.

Sinds een aantal jaren heeft het NIFP een taak bij de bemiddeling van gedragsdeskundige rapportages in het civiele jeugdrecht. Het is een taak die lastige dilemma's met zich meebrengt. In deze bijdrage wil ik die uitdaging voor het NIFP toelichten. Ik zal onder andere een casus presenteren waarin zowel in een civielrechtelijk als in een strafrechtelijk kader werd gerapporteerd. Ik hoop daarmee de dilemma's, die bij rapporteren in het civiele jeugdrecht spelen, over het voetlicht te brengen.

* Ineke Troost is als kinder- en jeugdpsychiater verbonden aan het Nederlands Instituut voor Forensische Psychiatrie en Psychologie Groningen, Friesland en Drenthe 


\section{Het NIFP en het landelijk kader Forensische Diagnostiek in de jeugd- zorg}

Vanaf 1 januari 2005 geldt in het gehele land het 'Landelijk kader Forensische Diagnostiek in de jeugdzorg', afgekort: 'landelijk kader'. Voor deze datum waren er geen landelijk bindende afspraken over de forensische diagnostiek voor jeugdigen. De forensische diagnostiek voor jeugdigen is te onderscheiden in een strafrechtelijk en een civielrechtelijk deel. In 1997 werd door de werkgroep 'Corona' een aantal problemen met de forensische diagnostiek voor jeugdigen geïnventariseerd. Deze werkgroep constateerde dat de forensische diagnostiek niet eenduidig was omschreven. Daarnaast werd door de gebruikers (rechtbank, Openbaar Ministerie, Raad voor de Kinderbescherming, gezinsvoogdijinstellingen) geklaagd over de kwaliteit van de forensische rapportages: diagnostische instrumenten werden niet goed gebruikt en de tijd nodig voor de oplevering van de rapportages (de doorloopsnelheid) was te lang. Daardoor werden beslissingen uitgesteld. Er was voorts een tekort aan rapporteurs, vooral aan kinder- en jeugdpsychiaters. De organisatie van de forensische diagnostiek in het jeugdstrafrecht verschilde per arrondissement in Nederland. De strafrechtelijke rapportages over jeugdigen werden op dat moment nog niet overal door het NIFP bemiddeld. Er was ook niet afgesproken wie de kwaliteit van de rapportages bewaakte. Deze situatie had tot gevolg dat er geen landelijke uniformiteit was. Dat zou kunnen leiden tot rechtsongelijkheid. Er waren ook nog nauwelijks kinder- en jeugdpsychiaters en -psychologen in dienst bij het NIFP.

Bij de diagnostiek in het civiele jeugdrecht werden nog meer problemen geconstateerd. Gezinsvoogdijpupillen bleken moeilijk toegang te krijgen tot de jeugd geestelijke gezondheidszorg. Er werden daarom rapportages door de gezinsvoogdijinstellingen aangevraagd die meer met hulpverlening dan met te nemen rechtelijke beslissingen van doen hadden. Ook was er soms sprake van 'verlegenheidsdiagnostiek': de moeilijke beslissing werd door de gezinsvoogdijinstelling doorgeschoven naar de onafhankelijke rapporteur of het onderzoeksbureau. Rapporteurs waren bezorgd om aangeklaagd worden door de onderzochte ouders. Deze zorg bestaat overigens nog steeds. Dit is vooral het geval bij conflictueus verlopende echtscheidingszaken.

Op initiatief van het ministerie van Justitie zijn in 2002 de betrokken ketenpartners om de tafel gaan zitten om afspraken te maken over de forensische diagnostiek. Het resultaat van deze gesprekken is gebundeld in het landelijk 
kader. Dit landelijk kader is gefaseerd ingevoerd. Het doel van het landelijk kader is om bij te dragen aan een verbetering van de kwaliteit en tijdigheid van forensisch diagnostische rapportages over jeugdigen, door middel van een duidelijke verdeling van taken, verantwoordelijkheden en bevoegdheden van de betrokken ketenpartners en duidelijke kwaliteitscriteria. Het landelijk kader geldt voor de 'justitiepartners', dat zijn de rechtbank, het Openbaar Ministerie, de Raad voor de Kinderbescherming en het NIFP. Er is dringend gevraagd aan het Bureau Jeugdzorg (waarin de gezinsvoogdijinstellingen sinds 2005 zijn opgenomen) om zich aan dit kader te committeren. Voor dit bureau, als instelling die onder de provincie valt, is het kader niet verplichtend.

Het NIFP kreeg een sleutelrol bij de invoering van het landelijk kader. Het NIFP heeft de volgende drie taken: het adviseren van de aanvragers van forensische diagnostiek, het bemiddelen van rapportages naar rapporteurs en het vervolgens toetsen van deze rapportages op basis van methodologische criteria. Het NIFP heeft daarmee een taak op een voor haar nieuw terrein, namelijk de bemiddeling van de rapportages in het civiele jeugdrecht.

\section{In welke situaties wordt een civielrechtelijke rapportage aangevraagd?}

De opdrachtgevers consulteren het NIFP wanneer zij denken dat een gedragsdeskundige rapportage een duidelijke meerwaarde heeft, bij een door hen te nemen beslissing. De opdrachtgevers zijn in het civiele veld: de kinderrechter, de Raad voor de Kinderbescherming en de gezinsvoogdijinstelling als onderdeel van het Bureau Jeugdzorg.

De omstandigheden waaronder rapportages nodig zijn, doen zich in drie situaties voor. De eerste is bij de rechterlijke beslissing inzake gezagsvoorziening en omgangsregeling en hoofdverblijfplaats van kinderen na (echt)scheiding (scheiding en omgang). Bijvoorbeeld in het geval dat de moeder het bezoek van de kinderen aan vader tegenhoudt omdat zij hem beschuldigt van gewelddadigheden nu of in het verleden. De tweede situatie waarin soms wordt gerapporteerd betreft adoptie (geschiktheid als adoptieouder), bijvoorbeeld in het geval de toekomstige adoptievader een strafblad heeft in de late adolescentie. De derde en tevens belangrijkste categorie betreft de kinderbeschermingsmaatregelen (ondertoezichtstelling en machtiging uit huisplaatsing, maar ook de ontheffing/ontzetting uit het ouderlijke 
gezag). Bijvoorbeeld indien een jongere op civielrechtelijke titel in een gesloten instelling wordt geplaatst.

Belangrijk om te vermelden is dat de noodzaak tot forensische diagnostiek in deze categorie tot voor kort niet wettelijk verankerd was. Daarin is per 1 januari 2008 verandering gekomen. ${ }^{1}$ Het nieuwe artikel 29b van de Wet op de Jeugdzorg schrijft voor dat een gedragswetenschapper moet instemmen met het verzoek tot gesloten plaatsing. Deze gedragswetenschapper moet de jeugdige daartoe kort tevoren hebben onderzocht. ${ }^{2}$ In de nieuwe wettelijke regeling heeft de gedragswetenschapper dus een duidelijke plaats gekregen. ${ }^{3}$

Na de aanvraag tot rapportage vindt overleg tussen het NIFP en de opdrachtgever plaats. Gezamenlijk wordt de aanvraag in het indicatieoverleg besproken, telefonisch of face to face. De belangrijkste vraag is of het onderzoek een meerwaarde zal hebben en zal bijdragen aan een gewogen justitiële beslissing. Belangrijk is dat onderscheid wordt gemaakt tussen reguliere zorgdiagnostiek en forensische beslissingsdiagnostiek. De forensische diagnostiek is bedoeld om de rechter voor te lichten en te adviseren. Deze rapportage wordt gebruikt of zal waarschijnlijk gebruikt worden op een zitting. Dat laat onverlet dat er ook vragen in het kader van begeleiding en behandeling gesteld en beantwoord kunnen worden. Voor de gezinsvoogdijinstelling is het onderscheid niet altijd gemakkelijk. Zij moet immers voortdurend (moeilijke) beslissingen nemen. Zo kan er al een machtiging uithuisplaatsing voor een jaar zijn, maar weet de gezinsvoogd niet goed waar hij een kind moet plaatsen. Beslissingsdiagnostiek is dan ook nergens strikt omschreven, hoewel het NIFP criteria heeft opgesteld. Uiteindelijk zal elke ondertoezichtstelling na een jaar eindigen en bij een verlenging moeten worden beoordeeld door de kinderrechter.

In het indicatieoverleg wordt ook geadviseerd wie het onderzoek zal uitvoeren. Dat kan een GZ-psycholoog en/of een psychiater zijn. Ook wordt een beslissingsgerichte vraagstelling opgesteld. Wanneer alle gegevens van de

1 Wet op de jeugdzorg, Staatsblad 2007, 578 en 579. Het betreft de aanvulling van de Wet op de jeugdzorg met titel IVa: 'Gesloten jeugdzorg'. De wetswijziging is een gevolg van de beslissing om de jongeren met een civiele maatregel apart van de jongeren met een strafrechtelijke status te plaatsen.

2 Zie voor een nadere toelichting de brief van de minister van Jeugd en Gezin van 27 februari 2008, Kamerstukken II, 30644, nr. 27.

3 Op dit moment vullen de bureaus jeugdzorg deze verplichting nog verschillend in. 
opdrachtgever bij het NIFP zijn, wordt het onderzoek bemiddeld naar een van de schaarse onafhankelijke rapporteurs of een rapportagebureau. Deze rapporteur gaat aan het werk en levert een conceptrapportage in bij het NIFP. Deze rapportage wordt vervolgens getoetst op kwaliteit aan de hand van criteria. De rapporteur brengt al dan niet veranderingen aan en legt de rapportage ter inzage voor aan de onderzochten. Deze kijken daar over het algemeen kritisch naar. De rapportage wordt uiteindelijk ingeleverd bij het NIFP en doorgestuurd naar de opdrachtgever.

Er wordt nog niet in het gehele land door het NIFP bemiddeld. Dit heeft verschillende redenen, welke binnenkort worden onderzocht. In 2008 wordt begonnen met de officiële evaluatie van het landelijk kader. De volgende redenen kunnen aan de orde zijn. Het landelijk kader blijkt onbekend bij een aantal van de bureaus jeugdzorg; de implementatie van het landelijk kader is niet optimaal georganiseerd (de organisatie werd aan het NIFP overgelaten zonder dat daarvoor extra financiële middelen waren vrijgemaakt); in een aantal arrondissementen had het NIFP nog niet de vrouw- of mankracht om het voortouw te nemen. De nieuwe taak van bemiddeling in een civielrechtelijk kader blijkt vooralsnog veel tijd te kosten; een aantal zaken is nog niet goed geregeld. Ten slotte is het Bureau Jeugdzorg niet verplicht om mee te doen. Voor een aantal bureaus jeugdzorg geldt dat zij bemiddeling via het NIFP een omweg vinden, die tijd kost en weinig oplevert. Daarnaast hebben zij momenteel te maken met meerdere veranderingen in wetgeving en organisatie, die prioriteit krijgen.

Uit de cijfers van 2006 blijkt dat de belangrijkste aanvrager van civielrechtelijke rapportages het Bureau Jeugdzorg is. Daarna volgt de Raad voor de Kinderbescherming en vijf procent van de rapportages wordt door een kinderrechter aangevraagd. Deze theoretische inleiding zal ik nu inzichtelijker te maken aan de hand van een voorbeeld ontleend aan mijn praktijk.

\section{De casus}

Bij een vier maanden oud meisje worden door de kinderarts vanaf de leeftijd van één maand op verschillende momenten diverse botbreuken geconstateerd. Het meisje wordt enkele maanden opgenomen in een ziekenhuis met toestemming van de ouders. Zij krijgt in deze periode geen nieuwe botbreuken. De artsen gaan uit van kindermishandeling. De ouders ontkennen dit. Er 
wordt een melding gedaan bij het Algemeen Meldpunt Kindermishandeling (AMK). Het AMK speelt de zaak door aan de Raad voor de Kinderbescherming, en deze instelling verzoekt de kinderrechter om een voorlopige ondertoezichtstelling en een voorlopige machtiging uithuisplaatsing. Het meisje wordt na ontslag uit het ziekenhuis geplaatst in een pleeggezin. De ouders zijn het hier niet mee eens. De Raad voor de Kinderbescherming doet tegelijkertijd aangifte bij de politie.

De kinderrechter spreekt de ondertoezichtstelling uit voor een periode van één jaar en verleent de machtiging uithuisplaatsing voor een periode van drie maanden. De kinderrechter vraagt tijdens de zitting aan de ouders of zij wellicht onbewust hun dochtertje verwond hebben. Mocht dat zo zijn, dan kan - wat betreft de kinderrechter - het kindje met hulpverlening teruggeplaatst worden. De ouders ontkennen dat iets dergelijks is gebeurd. De kinderrechter stelt dat er binnen de drie maanden duidelijkheid moet komen over de volgende zaken: wat levert de aangifte van de Raad voor de Kinderbescherming bij de politie op en wat komt er uit het onderzoek via het NIFP. De vraag die door het onderzoek van het NIFP beantwoord moet worden is, in hoeverre de ouders geschikt en in staat zijn om hun dochter een veilig thuis te bieden. De kinderrechter overweegt hierbij dat, wanneer tegen het einde van deze termijn van drie maanden nog geen resultaten zoals hiervoor bedoeld bekend zijn, rekening gehouden moet worden met de mogelijkheid dat hij zal oordelen dat een langere uithuisplaatsing niet meer gerechtvaardigd is.

De Raad voor de Kinderbescherming en de gezinsvoogdijinstelling vragen samen civielrechtelijke rapportage aan bij het NIFP. Er wordt een multidisciplinair onderzoek van beide ouders aangevraagd. De beschikking van de kinderrechter dwingt tot handelen en er wordt een onderzoek uitgevoerd. Uit het civielrechtelijke rapport van de psycholoog en psychiater blijkt het volgende. De ouders zijn niet eerder met het strafrecht in aanraking geweest. Vader functioneert op een verstandelijk beperkt niveau. Hij is op de leeftijd van twee jaar geadopteerd. Hij is bekend met explosief agressief gedrag. In de kindertijd is hij onderzocht door een kinderpsychiater en werden een ontwikkelingsstoornis en tics geconstateerd. Moeder functioneert op een nog lager verstandelijk niveau: $\mathrm{zij}$ is licht verstandelijk gehandicapt. Zij kende een moeilijke jeugd met traumatische ervaringen. Zij is een lieve, maar passieve vrouw die zich gemakkelijk laat beïnvloeden. Ze heeft een zoon uit een eerdere relatie. Deze jongen is lichamelijk en verstandelijk gehandicapt. 
Vader en moeder ontmoetten elkaar toen vader ging werken bij de vader van moeder. Zij kregen een relatie en gingen samenwonen. Tijdens de eerste maanden van de nieuwe relatie zijn er problemen met de vader van het oudste kind, de ex-man van moeder. Wanneer zij zeven maanden zwanger is, merkt moeder de zwangerschap van het betrokken meisje voor het eerst op. De ouders hadden abortus willen plegen wanneer dit, gezien de duur van de zwangerschap, gekund had.

De rapporteurs vinden het moeilijk om uitspraken te doen. Ze treffen ontkennende ouders met veel problemen. Zij beschikken niet over de medische informatie van de kinderarts. Deze informatie is namelijk naar een kinderartsdeskundige gestuurd. Deze is door het Openbaar Ministerie gevraagd op te treden als getuige-deskundige. Bovendien kampen ze met de tijdsdruk. Ze laten in het midden of er toch geen sprake is van een medische oorzaak voor de botbreuken. Ze stellen dat, indien het meisje terug gaat naar haar ouders, er forensisch psychiatrische behandeling moet komen voor de vader en opvoedingsondersteuning in de thuissituatie. De beslissing of het meisje teruggeplaatst kan worden laten zij, vooral vanwege de vraag wat er nu precies gebeurd is, over aan de kinderrechter.

De kinderrechter beslist enkele maanden na uitbrengen van de rapportage dat het meisje terug geplaatst moet worden naar de beide ouders. De gezinsvoogdijinstelling is het hier niet mee eens. Zij spant een kort geding aan. In kort geding krijgt de gezinsvoogdijinstelling gelijk en blijft het kind in het pleeggezin. De uitkomst van het politieonderzoek is ondertussen dat de vader als verdachte wordt aangemerkt. Hem wordt ten laste gelegd dat hij in een periode van twee maanden opzettelijk en met voorbedachten raad, zwaar lichamelijk letsel heeft toegebracht aan zijn kind. Het NIFP krijgt dan de opdracht van de officier van justitie om in de strafrechtelijke zaak multidisciplinair te rapporteren. Vader bekent nu wel. Hij geeft toe dat de bij hem geconstateerde ontwikkelingsstoornis - voornamelijk de tics - maakt dat hij te ruw met zijn kind kan zijn omgegaan. De psychiater treft een ontoegankelijke man. Hij zegt: "Ik heb wel bekend, maar ik ben niet schuldig". Vanwege de complexe gezinssituatie en het feit dat de psychiater geen tics ziet bij vader, stellen de psychiater en psycholoog voor om vader klinisch te laten observeren. Beide deskundigen oordelen dat het recidiverisico hoog is.

De plaatsing voor een klinische observatie heeft wat voeten in aarde omdat de man geschorst was uit preventieve hechtenis. Tijdens deze schorsing 
waarbij vader thuis is, bereiken de gezinsvoogdijinstelling signalen dat het andere kind verwaarloosd wordt. Vanwege deze zorgen wordt de oudste zoon met een machtiging, dus getoetst door de kinderrechter, uit huis geplaatst. Vader wordt opgenomen in een kliniek, en er wordt een rapport uitgebracht. Ten aanzien van de diagnostiek komen de onderzoekers niet tot andere bevindingen dan de eerste onderzoekers. De onderzoekers vinden het onverantwoord dat vader een opvoedersrol op zich neemt. De conclusie luidt dat er sprake is van een stoornis die maakt dat het telastegelegde, indien bewezen, sterk verminderd toegerekend kan worden. Het recidivegevaar wordt hoog geschat en daarom wordt een terbeschikkingstelling met dwangverpleging geadviseerd.

Het vonnis van de strafrechter luidt dat de vader schuldig wordt bevonden. De rechtbank gebruikt de verklaring van de moeder dat betrokkene twee keer alleen met het slachtoffer alleen is geweest, waarna de botbreuken werden geconstateerd, voor het bewijs. Niemand anders is op die momenten alleen met de baby geweest. Een kinderarts die als forensische pediatrisch geneeskundige onderzoek heeft verricht, concludeert dat het bij het slachtoffer geconstateerde letsel slechts veroorzaakt kan zijn door uitwendig fysiek geweld. Het vonnis luidt twee jaar gevangenisstraf. De motivering van de strafmaat is dat de rechtbank de conclusie ten aanzien van de stoornis en toerekeningsvatbaarheid overneemt en dit verdisconteert in de lengte van de gevangenisstraf. De straf zou volgens het vonnis anders vijf jaar zijn geweest. De rechters oordelen over de kans op herhaling het volgende: zij gaan ervan uit dat de vader niet eerder gewelddadig is geweest naar kinderen. De rechtbank acht naar de huidige stand van zaken de kans volstrekt uitgesloten dat het slachtoffertje, gelet op de delicten van haar vader, ooit nogmaals aan verdachtes zorgen wordt toevertrouwd. Voor zijn dochtertje bestaat daarom geen herhalingsgevaar. Niet op voorhand kan worden aangenomen dat de unieke omstandigheden waaronder verdachte de onderhavige delicten heeft gepleegd zich ten aanzien van een ander kind opnieuw zullen voordoen. Vader was onvoorbereid op het vaderschap dat bovendien in een zeer onrustige periode viel. Mocht hij opnieuw vader worden dan kan dat beter voorbereid worden en kan er hulp bij de opvoeding worden gegeven. De rechtbank vindt de kans op recidive met deze hulp klein genoeg om geen terbeschikkingstelling op te leggen. 


\section{Evaluatie van de casus}

In deze casus is al met al drie keer gerapporteerd door pro-justitia rapporteurs. De eerste keer binnen het civiele jeugdrecht en vervolgens twee keer in een strafrechtelijk kader. We lopen de diverse stappen in het proces nog eens na. Wat kan gezegd worden over de indicatie van dit civiele onderzoek? Het voorstel voor rapportage kwam van de gezinsvoogdijinstelling en de Raad voor de Kinderbescherming. De kinderrechter nam dit over en stelde een termijn. De gezinsvoogdijinstelling hoopte dat zij met een gedragsdeskundige rapportage de kinderrechter beter kon overtuigen dat dit meisje niet teruggeplaatst moest worden. Dat is niet gelukt. Mogelijk schoot de inhoudelijke voorlichting aan de kinderrechter hier tekort. ${ }^{4}$ Hier was overigens sprake van beslissingsdiagnostiek. De kinderrechter maakte duidelijk dat de beslissing over de verlenging van de machtiging uithuisplaatsing gekoppeld was aan het beschikbaar zijn van rapportage. Mijn inziens had beter gewacht worden op de uitkomst van het politieonderzoek en eventueel strafrechtelijk onderzoek. De ernst en de regelmaat van de in het ziekenhuis vastgestelde mishandeling bij dit zeer jonge meisje en de ontkenning van de ouders maakt het risico groot en had voldoende kunnen zijn voor voortgezette uithuisplaatsing. Civielrechtelijke rapportage voegt op zo'n moment niet zo veel toe. Het was volgens mij niet te verwachten dat de ouders openheid van zaken zouden geven, toen tegelijkertijd een politieonderzoek werd gestart. Er had dan gewacht kunnen worden op de uitkomst van een eventueel strafrechtelijk onderzoeken strafzitting, waarin een uitspraak gedaan had kunnen worden over wie de dader was.

Het gaat echter om twee volstrekt verschillende procedures. Meestal komt het in kindermishandelingzaken niet tot een strafzaak, en moet er dus wel in een civielrechtelijk kader beslist worden. ${ }^{5}$ Er wordt niet vaak aangifte gedaan en de bewijsvoering kan moeilijk zijn. Indien er wel een strafzaak komt, duurt het wachten op de uitkomst daarvan te lang om tijdig in te kunnen

4 Voor het rapport De positionering van de jeugdrechter, geschreven in opdracht van de Raad voor de Rechtspraak in 2006, is een enquête uitgevoerd onder kinderrechters. Daaruit blijkt dat kinderrechters vaker vinden dat de volledigheid en bruikbaarheid van informatie van de externe partners beter kan.

5 In het actieplan aanpak kindermishandeling Kinderen veilig thuis van het Ministerie voor Jeugd en Gezin van juli 2007, wordt gemeld dat de aanpak van kindermishandeling bij uitstek ook een zaak is van het strafrecht. In overleg met het college van procureursgeneraal wordt bezien of een aparte aanwijzing kindermishandeling nodig is of dat uitbreiding van de als bestaande aanwijzing huiselijk geweld volstaat. 
grijpen. In de besproken casus werd het strafrechtelijke vonnis anderhalf jaar na de uithuisplaatsing van het meisje uitgesproken. Dit is een lange periode op het leven van een baby. De ontwikkeling van een kind staat immers niet stil. Daarom is zo snel mogelijk duidelijkheid zeer gewenst voor kinderen.

\section{Wat kan gezegd worden over de uitvoering van een onderzoek?}

Uitgangspunt bij civielrechtelijk rapporteren is het belang van het kind. Het gaat eigenlijk altijd om de vraag of de opvoedingsomstandigheden waaronder dit kind moet opgroeien voldoende zijn en het kind er geen emotionele of lichamelijke schade van ondervindt.

Bij het onderzoek gaat het niet alleen om de behoeften van het kind, maar ook om de veiligheid van en de risico's voor het kind. Die zijn niet gemakkelijk te bepalen. Risicotaxatie-instrumenten in de jeugdzorg zijn nauwelijks ontwikkeld. Rapporteurs beschikken vaak niet over alle informatie. In deze zaak hadden de rapporteurs geen inzage in het kindergeneeskundige dossier en misten daarmee voor hen essentiële informatie. Rapporteurs kunnen eventueel zelf informatie opvragen, maar dat kost tijd. De rapporteur heeft bovendien toestemming nodig van de ouders. Die wordt niet altijd gegeven, in het bijzonder niet wanneer deze informatie negatief kan uitpakken voor de onderzochte ouder.

Rapporteurs in civielrechtelijke zaken zijn voorzichtig met het doen van uitspraken die zij onvoldoende kunnen onderbouwen. Rapporteren in het civiele jeugdrecht is klachtgevoelig. De ouders voelen zich in hun grondrechten aangetast. In hun ogen worden kinderen 'afgenomen' op 'onduidelijke gronden'. De druk en verwachtingen van het rapport zijn daarom groot. Er wordt wel eens gezegd dat het civielrechtelijke onderzoek een kans is voor ouders om te laten zien dat ze het opvoeden wel kunnen. Bij een advies dat het beleid van de opdrachtgever ondersteunt, is er een risico dat de negatieve gevoelens op de rapporteur gericht worden. Dat kan uitmonden in een klacht bij een tuchtrechter of een andere instantie.

Ouders die meewerken aan een civielrechtelijke rapportage kunnen gedurende het onderzoeksproces van mening veranderen. Hun aanvankelijk gegeven toestemming om het eindrapport aan de opdrachtgever te geven, kan worden ingetrokken. Ze maken dan gebruik van het blokkaderecht. De rapporten worden, anders dan bij de strafrechtelijke rapporten, zorgvuldig gelezen door 
de onderzochte ouders. Een mogelijkheid om blokkade te voorkomen is om de opmerkingen van de ouders als bijlage mee te sturen met het onderzoek. Blokkering kan het nemen van de beslissing vergemakkelijken. De opdrachtgever en ook de kinderrechter mogen er in dat geval van uit gaan dat het rapport geen gunstige uitkomst voor de onderzochte bevat. Overigens kan de rapporteur het blokkaderecht naast zich neerleggen indien hij of zij vindt dat het betreffende kind ernstige risico's loopt. Dit is een moeilijke afweging voor een rapporteur omdat hij ervan uit kan gaan dat de kans dat hij zich bij de tuchtrechter moet verantwoorden groot is.

In deze zaak vonden de deskundigen het emotioneel zwaar om te rapporteren. De meeste rapporteurs in het civiele jeugdrecht ervaren dit werk als emotioneel meer belastend dan rapporteren in het jeugdstrafrecht. De kinderbescherming werkt bij uitstek met onzekerheid, ambiguïteit en feilbaarheid. De kennis is beperkt, voorspellingen zijn voor de toekomst allerminst perfect. Sterke emoties spelen vaak een rol, er is sprake van conflict van belangen tussen ouders en kwetsbare kinderen. Er is veelal sprake van tijdsdruk. Risicotaxatie is nieuw in kinderbescherming. Het gaat altijd over de minst slechte, dus een negatieve uitkomst. De publieke opinie verwacht terecht, zeker op dit moment, een hoge standaard, maar die is moeilijk te bereiken. Het doel van de kinderbescherming is namelijk niet alleen het minimaliseren van gevaar voor kinderen, maar ook maximaliseren van welzijn van kinderen.

Kinderen uithuisplaatsen bij kindermishandeling is een oplossing, maar is het verblijf van kinderen in instellingen een goed alternatief? Er zijn te weinig pleeggezinnen en de plaatsing van oudere kinderen is daarom moeilijk. De ouders die vandaag worden onderzocht met de vraag of ze een risico vormen voor hun kind, zijn de partners van morgen om mee samen te werken om het welzijn van hun kinderen te verbeteren. Ouders die mishandelen, ervaren de opvoeding over het algemeen als zwaar. Deze ouders hebben steun nodig om goed te kunnen opvoeden. Het Afrikaans gezegde: "You need a village to raise a child", blijft onbetwist. Ouders zullen nog moeilijker te bereiken zijn, wanneer zij worden gestigmatiseerd als daders. Deze dilemma's gelden niet alleen voor de werkers binnen de jeugdbescherming, maar ook voor de rapporteurs.

In de besproken casus heeft het mij verbaasd dat het civiele proces zo volstrekt los leek te staan van het strafrechtelijke proces. In deze zaak deden de rechters uitspraken, die beslissingen van hun collega-rechters op een ander 
terrein konden beïnvloeden. Zo ging de civiele rechter er voor de strafzitting van uit dat er sprake was van kindermishandeling gepleegd door (tenminste) één van de ouders. De strafrechters namen aan dat deze vader nooit meer voor zijn dochtertje zou zorgen, terwijl de civiele rechter haar had willen terugplaatsen bij de ouders. Vaak wordt bij kindermishandeling uitgegaan van een beperkte definitie van kindermishandeling. Er wordt dan alleen lichamelijke mishandeling onder verstaan en niet de (veel vaker voorkomende) emotionele verwaarlozing en/of -mishandeling. In deze zaak zijn de gedragingen naar het andere kind door het Openbaar Ministerie niet gevoegd. Er was ook geen aangifte gedaan. Geen van de strafrechtelijke rapporteurs heeft met de gezinsvoogdijinstelling gesproken. De civiele rapportage maakte wel deel uit van de stukken van de strafzaak.

\section{Conclusies en aanbevelingen}

Adviseren, bemiddelen en toetsen als NIFP-medewerker in het civiele jeugdrecht is een uitdaging. Onverwachte dilemma's duiken op, waarvan ik er in dit artikel een aantal heb genoemd. Civiele bemiddeling vraagt veel overleg en tijd. Geen zaak is tot nu toe dezelfde en de samenwerking met de nieuwe ketenpartner - de gezinsvoogdijinstelling - komt steeds beter uit de verf. Het NIFP heeft als 'het kennisinstituut op het gebied van forensische diagnostiek' zeker een taak om ook deze rapportages te bemiddelen. Het NIFP heeft niet alleen een poule met jeugdrapporteurs, maar ook rapporteurs voor volwassenen. In het recente verleden werden in het civiele jeugdrecht vooral onderzoeken van kinderen aangevraagd. Vaak gaat het echter vooral om de vraag naar ouderschapskwaliteiten en risico's en dan behoren de ouders onderwerp van onderzoek te zijn. Dat betekent dat er behoefte is aan deskundigen die over volwassenen kunnen rapporteren. Op dit moment hebben de rapporteurs die volwassenen onderzoeken het gevoel dat zij geen of weinig verstand hebben van de effecten van psychopathologie op de opvoedingscapaciteiten van ouders. Soms hebben kinder- en jeugdrapporteurs weer net te weinig inzicht in de stoornissen van volwassenen. Een oplossing zou kunnen zijn om een 'combinatie' van beide disciplines te laten rapporteren.

Belangrijk is verder dat de rechtspositie van de rapporteur in het civiele jeugdrecht beter gewaarborgd wordt. Dit verlaagt de drempel om te gaan rapporteren. 
Ten slotte ben ik er voorstander van dat het bevel tot deskundigenonderzoek wordt verleend door de kinderrechter. Ik zie daarin de volgende voordelen: er is geen discussie meer of het zorg- dan wel beslissingsdiagnostiek betreft. De kinderrechter als opdrachtgever heeft een neutrale rol en is niet betrokken in een strijd met de ouders, die soms ten grondslag ligt aan een onderzoek. Ten slotte heeft de kinderrechter meer gezag, waardoor ouders mogelijk sneller zullen meewerken en de rapportage minder zullen blokkeren. De emotionele druk om te rapporteren in deze schrijnende civielrechtelijke zaken zal door de verandering van opdrachtgever echter niet verminderen.

Vrij, naar Cees Buddingh, eindig ik met het volgende gedichtje:

\author{
Je vader trekt flessen \\ Je moeder schaatst scheef \\ Maar het blijven jouw ouders \\ Zolang als je leeft.
}

Literatuur:

- Actieplan aanpak kindermishandeling, Kinderen veilig thuis, Programma Ministerie Jeugd en gezin, 5 juli 2007.

- N. Duits, J.A.C. Bartels, en W.B Gunning. Jeugdpsychiatrie en recht, Assen: Koninklijke van Gorcum BV 2004.

- Forensische diagnostiek, een zorg voor de jeugdzorg, werkgroep Corona. Samenwerking VWS en Justitie, Den Haag, februari 1997.

- D. Iwaniec, The emotionally abused and neglected Child. Identification, assessment, and intervention. A practise handbook, Chichester: John Wiley and Sons ltd, 2006.

- Landelijk kader Forensische Diagnostiek in de jeugdzorg. Eindversie, 29 juli 2002.

- E. Munro, Effective Child protection, Sage publications Ltd, 2003.

- Rapport: De positie van de kinderrechter, 2006

- A.J. Verheugt, Moordouders, kinderdoding in Nederland, een klinisch en forensisch psychologische studie naar de persoon van de kinderdoder, Assen: Koninklijke van Gorcum 2007. 